\title{
НЕЗАВИСИМЫЕ НЕФТЯНЫЕ КОМПАНИИ РОССИИ В 2020 ГОДУ: РЕЗУЛЬТАТЫ ХОЗЯЙСТВЕННОЙ ДЕЯТЕЛЬНОСТИ И ПРОБЛЕМЫ РАЗВИТИЯ
}

\author{
(C) 2021 Козеняшева М.M. \\ доктор экономических наук, профессор, Заведующая кафедрой МНГБ \\ РГУ нефти и газа (НИУ) имени И. М. Губкина, Россия, Москва \\ E-mail:mngb@gubkin.ru; mkozenyasheva@gmail.com \\ Советник по экономике «АссоНефть»
}

Статья посвящена анализу экономических условий функционирования средних и малых нефтегазовых компаний в России - сектору независимой нефтегазодобычи, в контексте новых условий: экономического кризиса, пандемии, условий сделки ОПЕК+, а также проблемам налоговой практики и возможностям их дальнейшего роста.

Ключевые слова: независимые нефтегазодобывающие компании, доходы недропользователя, льготы по НДПИ, доходы бюджета, новый налоговый расчет

В российском нефтяном комплексе наряду с крупными вертикально-интегрированными нефтяными компаниями (ВИНК) активно работают малые и средние нефтяные компании, которые условно можно объединить в сектор независимых нефтегазодобывающих компаний (ННК). ННК возникли в России в 90-е годы прошлого столетия в условиях либерализации экономического развития и складывания рыночных условий хозяйствования.

Сегодня в этот сектор входят компании, которые не аффилированы с ВИНК, не имеют государственного пакета в уставном капитале, не ведут деятельность на условиях СРП, т.е. работают за счет собственных средств и на свой финансовый риск занимаются разведкой и добычей нефти и газового конденсата, а также их реализацией на внутреннем и внешнем рынках. От российских ВИНК они отличаются не только масштабами деятельности, но, главным образом, тем, что такие компании не имеют собственной нефтепереработки и системы сбыта/продажи нефтепродуктов, т.е. эти компании монотоварны.

ННК работают в основном на мелких, сложных месторождениях, с высокой долей (около $75 \%)$ трудноизвлекаемых запасов. Средняя величина начальных извлекаемых запасов по лицензионным месторождениям по сектору $-4,8$ млн. тонн, а у ВИНК $-23,3$ млн. тонн [1]. Независимые нефтяные компании разрабатывают в основном молодые малоизученные месторождения со средней выработанностью 18\%, в то время как у ВИНК средняя выработанность запасов $-55 \%$
[2]. На протяжении 20 лет интереса к деятельности данного сектора никто не проявлял, более того, господствующей была позиция, что нефть в России должны добывать только крупные компании. Однако сегодня - это «резервный полк» развития российской нефтяной отрасли. Да и не только российской. Повышение роли НHК со всей очевидностью проявилось в результате сланцевого прорыва, который был совершен в США именно небольшими независимыми компаниями, которых в этой стране насчитывают порядка 7000 в отличие от России, где их число не превышает 250, из которых сегодня ведут добычу не более 130 [3].

Начиная с 2010 г. ситуация в российском нефтяном комплексе стала кардинально изменяться и в кругах отраслевой науки все больше стали говорить о необходимости смены самой парадигмы его развития. Суть новой парадигмы четко выражена в последних научных публикациях Академика РАН А. Э. Конторовича, который подчеркивает, что в настоящее время внимание следует уделять нетрадиционным геологическим источникам нефти, удалённым и шельфовым районам, а также мелким и мельчайшим резервуарам [4]. В России именно ННК обычно ведут деятельность на мелких месторождениях.

Однако усиление роли независимых малых и средних компаний - это общемировая тенденция и объективная закономерность, которая обусловлена следующим:

- эпоха обнаружения и разработки гигантских нефтяных месторождений в мире близится к завершению, налицо процесс «измельчения» 
открываемых месторождений. А разработка мелких месторождений - это исторически была прерогатива небольших нефтяных компаний;

- новые открываемые месторождения все более характеризуются понятием «ТРИЗы» трудноизвлекаемые запасы. И это также сфера специализации независимых компаний, поскольку самые крупные и продуктивные месторождения всегда доставались крупным ВИНК, в то время как ННК вынуждены были разрабатывать «неудобья»;

- у ННК, вследствие малых масштабов ниже транзакционные издержки, поэтому ННК более оперативны и эффективны особенно в условиях экономических и нефтяных кризисов, в периоды падении цен, что определяет экономическое развитие мировой нефтяной отрасли в последние годы, поскольку в небольшой хозяйствующей единице затраты крайне оптимизированы. Тем не менее, мировая практика свидетельствует, что этот сектор остается в фокусе поддержки со стороны государства.

Сектор ННК в России, в отличие от зарубежных юрисдикций, не имеет льготных условий развития, а принимаемые законы, регулирующие отношения в нефтегазовой сфере в РФ, в первую очередь, ориентированы на крупный нефтяной бизнес, и специфику малого бизнеса они не учитывают. Положение в секторе НHК особенно четко показывает, какие условия существуют в России для освоения новых месторождений нефти, особенно небольших.

Следует отметить, что в России сектор ННК, по своей природе, очень неоднороден, в нем есть компании, которые за счет своего последовательного органического роста, достигли средних уровней добычи. К таковым можно отнести, Иркутскую нефтяную компанию (ИНК), которая начинала с уровня добычи 30 тыс.т в 2000 г., а в 2020 г. ее добыча достигла почти 9 млн.т. [5]. Другим инструментом роста таких компаний является политика слияний и поглощений, которую активно реализует, например, АО «Русь-Ойл», годовой уровень добычи которой в 2020 г. составил 2,7 млн. тонн [6]. Однако в секторе ННК есть и очень маленькие компании, добыча которых не превышает 10 тыс. т в год. Количество этих компаний в 2020 году возросло до 52 против 45 в 2017 году.

В 2020 г. сектор ННК, как и вся нефтяная промышленность, развивался в непростых условиях, поскольку:
- и мировая нефтяная отрасль и российская серьезно пострадали от короновирусной инфекции и сковавшей пандемией экономический процесс роста;

- произошло резкое сокращение спроса на нефть, что, в первую очередь, было связано с ограничением движения транспорта. Для статистики: в России спрос на нефть упал примерно на 40\%, в США - на 20\%, Китае - на 13\% [7]. По данным МЭА в 2020 г. был зафиксирован рекордный спад спроса на нефть по сравнению с апреля 2019 года. Спрос упал на 29 млн. барр/сут.

- жесткая ценовая война также ухудшила положение России на мировом нефтяном рынке. Большие скидки на нефть, предоставляемые Сaудовской Аравией, снижали привлекательность российского сырья на целевых рынках и приводили к сильному удешевлению сорта Urals. B апреле 2020 г. его цена уже падала до исторических минимумов 1998 года в 8,48 долл./барр.

- помимо сверхнизких цен, на российскую нефтяную отрасль оказала давление необходимость быстрого сокращения добычи. По итогам апрельских встреч ОПЕК+ и министров энергетики G20 Россия взяла на себя самые большие объемы сокращения - в среднегодовом исчислении добыча нефти в России снизится на 0,95 млн. барр/сут., или на 45 млн. тонн [8].

- экономический кризис также был отягощен низким курсом национальной валюты, так, если в 2018 г. курс доллара к российскому рублю составил в среднем 62,69 рублей за доллар, а в 2020 г. - 72,32 рублей за доллар) [9]. Одновременно продолжился рост налоговой нагрузки, что вело к снижению прибыльности компаний. Кроме того, в результате проведения большого налогового маневра (БНМ) в нефтяной отрасли осложнилась работа независимых НПЗ - важных потребителей нефти, добываемой небольшими ННК.

Долгосрочным фактором, который и в дальнейшем будет оказывать влияние на развитие нефтегазового сектора, выступает политика западных стран и Японии, которые стремятся к глобальному сокращению использования нефти и газа. Так, итогом состоявшегося в сентябре 2020 г. саммита ООН по климату, стала договоренность 66 стран о достижении углеродной нейтральности.

Масштабное сокращение добычи и падение денежных потоков компаний неизбежно привели к сокращению бюджетов и пересмотру 
инвестиционных программ российских ВИНК (в частности, инвестиций в геологоразведку), к сокращению заказов для смежных отраслей. Но еще в более сложном положении оказались российские малые и средние нефтяные компании, а также компании с высокой долговой нагрузкой, поскольку у них запас прочности всегда более низкий.

В 2020 году в России, по данным ФГУП ЦДУ ТЭК (далее - ЦДУ ТЭК), в стране ведут деятельность по добыче нефти 188 компаний, не входящие в состав крупных вертикальноинтегрированных холдингов и ЦДУ ТЭК объединяет их всех под названием «Прочие производители». Однако эти компании зачастую являются аффилированными и структурами или дочерними предприятиями ВИНК. И таким образом, независимыми компаниями их назвать нельзя. По данным АссоНефть*, количество ННК, ведущих добычу нефти в стране, в 2020 г. составило 127. Разница в числовом составе ННК обусловлена следующими факторами: ряд компаний, которые ЦДУ ТЭК продолжает включать в группу независимых производителей, не могут быть отнесены к сектору ННК по причинам, указанным выше. Например, ООО «Сладковско-Заречное» входит в состав промышленно-финансовой группы «САФМАР» М.Гуцериева, контролирующей такие ВИНК, как «Русснефть» и «Нефтиса».

ЗАО ‘Чепецкое НГДУ’, которое ЦДУ ТЭК про- должает относить к Прочим производителям, вошло в состав Группы независимых добывающих компаний - УДС-нефть.

В 2020 г. ЦДУ ТЭК включило в состав независимых производителей нефти и ООО 'НКНП' («Новый поток»), однако данная компания является типичным представителем вертикальноинтеграционной структуры в нефтяном бизнесе, поскольку в ее состав входят как добывающие, так и перерабатывающие активы, в том числе Афипский и Марийский НПЗ, а также сбытовые структуры, в том числе: New Stream Trading AG, осуществляющий экспорт нефтепродуктов, ООО «АНПЗ-Продукт» - оптовую продажу нефтепродуктов в России, ООО «Нью Петрол Тюмень», занимающаяся розничной реализацией бензинов, дизельного топлива и сжиженных углеводородных газов в РФ

Кроме того в секторе ННК сформировались холдинги под единым руководством, которые включают в себя рад компаний, к таковым относится Иркутская НК, «Русь-Ойл» и ряд других. Поэтому реальное число компаний, которые входят в сектор ННК, значительно меньше. Условно все ННК можно объединить в 6 групп в зависимости от объемов добываемой ими нефти, что отражено в Таблице 1.

Из таблицы 1 следует, что если в 2019 г. объем добычи сектора ННК составил 22724 тыс. т., то в 2020 г. добыча заметно выросла и соста-

* Ассоциация независимых нефтегазодобывающих компаний.

Таблиц̧а 1. Динамика добычи нефти ННК в 2019 и 2020 гг. в разбивке по группам

\begin{tabular}{|c|c|c|c|c|c|}
\hline Название ННК & 2019 г. & 2020 г. & рост (тыс.т) & $\begin{array}{c}\text { темп роста } \\
(\%)\end{array}$ & $\begin{array}{c}\text { темп } \\
\text { прироста } \\
(\%) \\
\end{array}$ \\
\hline ИНК & 9052,43 & 8640,89 & 411,55 & 95,45 & $-4,55$ \\
\hline АО 'Русь-Ойл' & 2753,73 & 3077,73 & 324,00 & 111,77 & 11,77 \\
\hline $\mathrm{AO}$ 'PHГ' & - & 1059,64 & 1059,64 & & \\
\hline Итого Группа "А" - крупные ННК & 11806,16 & 12778,26 & 972,10 & 108,23 & 8,23 \\
\hline ЗАО 'Предприятие Кара-Алтын' & 517,11 & 509,21 & 7,90 & 98,47 & 1,53 \\
\hline Итого Группа "Б" от 0,5 до 1 млн. т. & 1015,60 & 509,21 & 506,39 & 50,14 & $-49,86$ \\
\hline Итого Группа "В" от 100 до 500 тыс. т & 7676,52 & 8662,96 & 986,44 & 112,85 & 12,85 \\
\hline Итого Группа "Г" от 50 до 100 тыс. т & 1381,25 & 1125,41 & 255,84 & 81,48 & $-18,52$ \\
\hline Итого Группа "Д" от 10 до 50 тыс. т & 679,40 & 633,14 & 46,26 & 93,19 & - 6,81 \\
\hline Итого Группа "Е" от 0,1 до 10 тыс. т & 164,97 & 159,93 & 5,05 & 96,94 & 3,06 \\
\hline ИТОГО сектор ННК & 22723,90 & 23868,90 & 1145,00 & 105,04 & 5,04 \\
\hline
\end{tabular}

Источник: рассчитано автором по данным ЦДУ ТЭК РФ - Добыча. [10]. 
вила 23868,8 тыс. т. Однако отметим, что этот показатель суммарного объема добытой нефти сектором ННК в 2020 г. значительно ниже, чем показатель, представленный в статистических бюллетенях ЦДУ ТЭК. Это обусловлено, во-первых, методологическими аспектами, т.е., количеством компаний, которые включаются в сектор ННК аналитиками ЦДУ ТЭК, и аналитиками АссоНефть. Объективным фактором, который привел к увеличению объемов добычи нефти сектором ННК в 2020 г. в сравнении с 2019 г., связан с началом промышленной эксплуатации разрабатываемых месторождений компанией АО «РНГ», которая по итогам 2020 г. добыла более 1 млн. т. В тоже время для большинства копаний в Группах «Б», «Г», «Д» И «Е», характерным стало, как следует из Таблицы 1 , сокращение добычи в сравнении с 2019 г. и темпы добычи ушли в отрицательную зону.

Добытая сектором ННК нефть поступает на внутренний рынок на переработку, а также может быть поставлена на экспорт. По данным АссоНефть в 2020 г. объемы поставок на внутренний рынок выросли в сравнении с показателями 2019 г. почти на 430 тыс. т, при этом темпы прироста составили около 3\% (Табл. 2). Однако этот общий тренд по-разному проявился в различных группах НHК.

Данные Таблицы 2 позволяют заключить, что в Группах «Б», «Г» и «Е» произошло заметное сокращение поставок, однако это в значитель- ной степени связано перегруппировкой компаний и их переходом по итогам добычи в 2020 г. на более высокую или более низкую позицию.

Наибольшие объемы добытой нефти компаниями сектора ННК поступают на следующие НПЗ: Хабаровский НПЗ, на который направляется приблизительно 1/4 часть всех поставок нефти. В 2020 г. возросла доля Новошахтинского ЗНП, который принимает порядка 17,7\% нефти, предназначенной для внутреннего рынка, доля Московский НПЗ приблизительно составляет $12 \%$, на неопределенные НПЗ отгружается порядка 10\%. Заметные объемы - 12-15\% - поступает на заводы переработки в Республику Татарстан. Суммарно все эти заводы принимают $75 \%$ всех объемов нефти, отгружаемых на внутренний рынок ННК. Обобщение этих данных позволяет сделать следующий вывод, в сложившихся условиях основная доля поставок нефти сектором ННК поступает на заводы вертикальноинтегрированных компаний (рис. 1).

Анализ динамики поставок нефти в разрезе по группам компаний позволяет выявить зависимость сектора от возможности и условий переработки нефти в России (рис. 2). Из диаграммы рис. 2 следует, что все группы ННК поставляют на внутренний рынок 50\% (Группа «А») и более от добываемой ими нефти. Кроме компаний группы «А», остальные ННК реализуют внутри страны значительно более $70 \%$ добываемой нефти. При этом компании с более низким

Таблица 2. Динамика поставок нефти на переработку компаниями секторам ННК в разбивке по группам в 2019 и 2020 гг.

\begin{tabular}{|c|c|c|c|c|c|}
\hline Название ННК & 2019 г. & 2020 г. & рост (тыс.т) & $\begin{array}{c}\text { темп роста } \\
(\%)\end{array}$ & $\begin{array}{c}\text { темп прироста } \\
(\%)\end{array}$ \\
\hline ИНК & 4560,00 & 4150,46 & 409,55 & 91,02 & - 8,98 \\
\hline АО 'Русь-Ойл' & 1600,00 & 2099,69 & 499,69 & 131,23 & 31,23 \\
\hline \multicolumn{6}{|l|}{ AO 'PHГ' } \\
\hline Итого Группа "А" - крупные ННК & 6160,00 & 6250,14 & 90,14 & 101,46 & 1,46 \\
\hline ЗАО 'Предприятие Кара-Алтын' & 749,12 & 498,44 & 250,68 & 66,54 & 33,46 \\
\hline Итого Группа "Б" от 0,5 до 1 млн. т. & 749,12 & 498,44 & 250,68 & 66,54 & 33,46 \\
\hline Итого Группа "В" от 100 до 500 тыс. т & 6143,00 & 7097,98 & 954,98 & 115,55 & 15,55 \\
\hline Итого Группа "Г" от 50 до 100 тыс. т & 1234,00 & 813,66 & 420,34 & 65,94 & 34,06 \\
\hline Итого Группа "Д" от 10 до 50 тыс. т & 543,13 & 603,23 & 60,10 & 111,07 & 11,07 \\
\hline Итого Группа "Е" от 0,1 до 10 тыс. т & 164,97 & 159,93 & 5,05 & 96,94 & 3,06 \\
\hline ИТОГО сектор ННК & 14994,22 & 15423,37 & 429,15 & 102,86 & 2,86 \\
\hline
\end{tabular}

Источник: рассчитано автором по данным ФГБУ «ЦДУ ТЭК» [11]. 


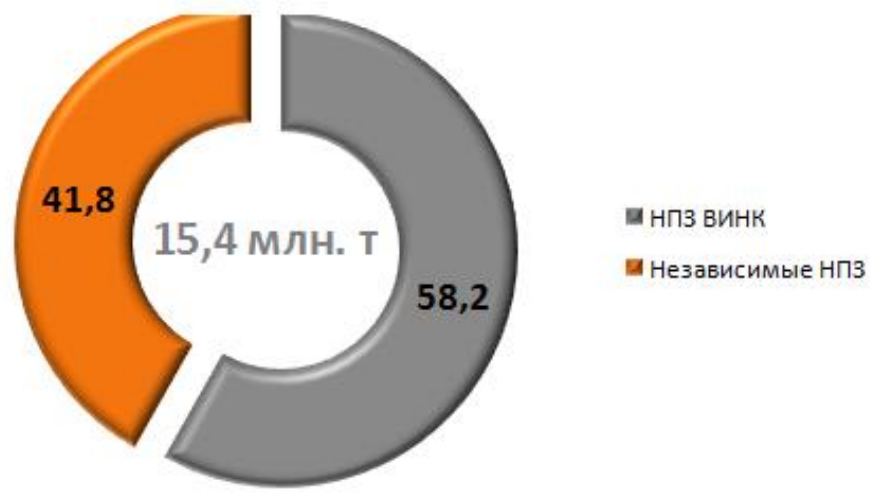

Puc. 1. Доля поставок нефти ННК на заводы ВИНК и на предприятия независимой переработки в 2020 г. (\%) Источник: рассчитано автором.

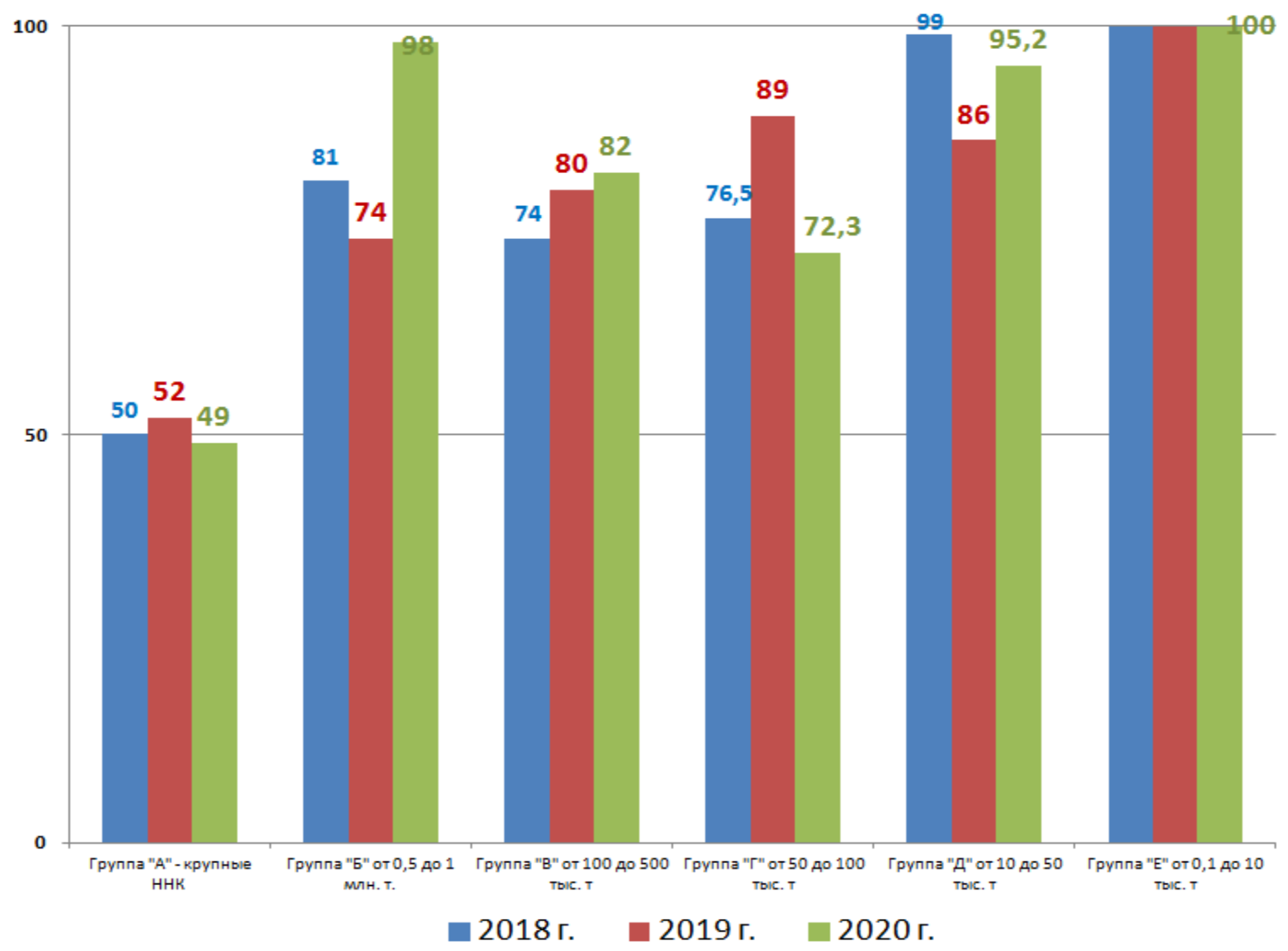

Puc. 2. Доля поставок на внутренний рынок по группам компаний в 2018, 2019 и 2020 г. (\%) Источник: рассчитано автором.

уровнем добычи в большей степени зависят от условий внутреннего рынка.

Другой опцией реализации добытой нефти являются поставки на экспорт. В 2019 г. сектором ННК было отгружено 8,32 млн. т, что на 914 тыс. т больше, чем в 2018 г., когда он составлял 7,4 млн. т. В 2020 г. на экспорт компаниями сектора ННК было отгружено 8,4 млн. т, т.е., почти на 86 тыс. т больше, чем годом ранее. В 2019 г. экспорт существенно вырос в направлении порта Козьмино (на более, чем 1 млн. т) и порта Приморск (на 152,6 тыс. т) в сравнении с показателями 2018 года. В 2020 г. существенно выросли отгрузки нефти в Белоруссию - объем экспорта достиг 241 тыс. т.

Главным направлением экспорта нефти как в 2019 г., так и 2020 г. остается порт Козьмино, доля поставок нефти в этом направлении дости- 
гает 76\%. В этом направлении ведут экспортные отгрузки компании Группы «А», для которых характерны, во-первых, большие объемы добычи нефти и, во - вторых, более широкие возможности производственной деятельности, включая экспортные операции.

В 2020 г. доля поставок нефти на экспорт через порт Приморск - один из главных экспортных артерий страны - была несколько меньше, чем годом ранее и составила 6,7\%, при этом выросла до 8,6\% доля поставки нефти на экспорт через порт Новороссийск (в 2019 г. она составляла 7,3\%). Таким образом, 2 порта, связывающие российскую нефть ННК с европейским рынком, сохраняют суммарную долю - приблизительно около $15 \%$.

В европейском направлении происходит отгрузка нефти и по нефтепроводу «Дружба». Доля экспорта нефти сектором ННК в страны Европы по н/П «Дружба» не превышает в настоящее время 7-8\%. Общая структура экспортных поставок ННК в 2020 г. отражена на рис. 3.

Значение экспортных операций для сектора ННК имеют не столь важное значение, как поставки на внутренний рынок, и это подтверждает динамика экспортных поставок в разбивке по группам сектора (рис. 4).

Из диаграммы рис. 4 видно, что экспорт неф-

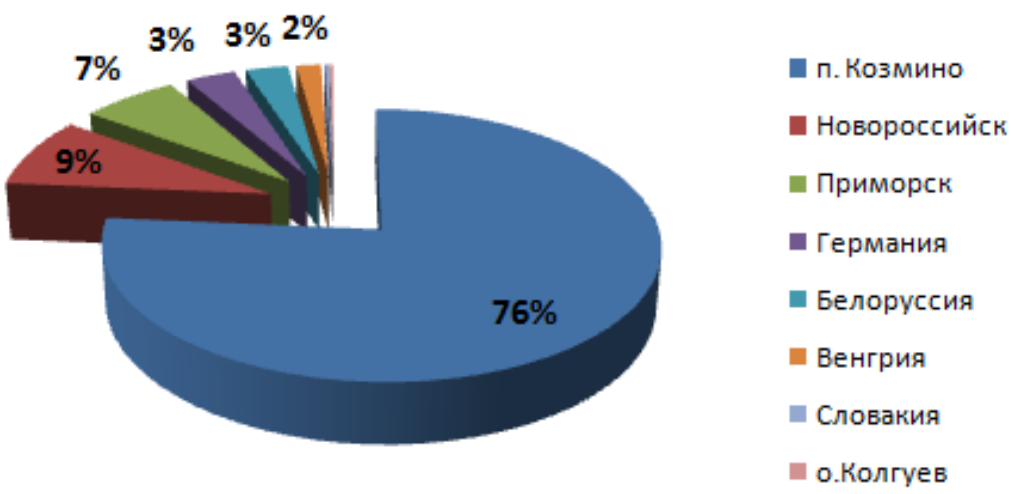

Puc. 3. Структура экспортных поставок ННК в 2020 году, (\%).

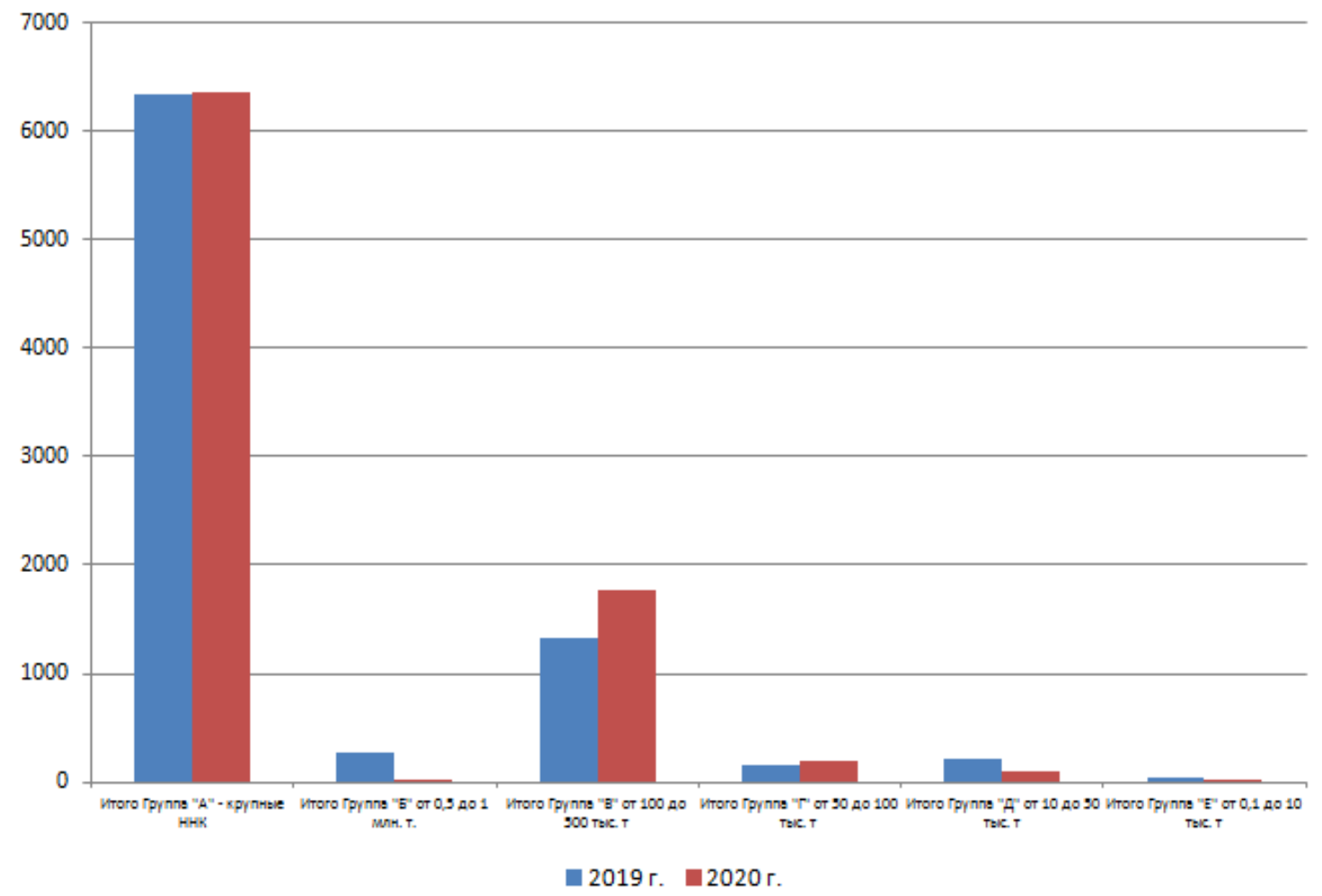

Puc. 4. Динамика экспортных поставок в разбивке по группам. Источник: рассчитано автором. 
ти осуществляет, главным образом, только Груп- экспортных операций крайне незначителен, попа «А», доля которой абсолютно превалирует. скольку небольшие компании, как правило не Определенные объемы экспортирует и группа располагают танкерными партиями и, следова«B», однако ее экспортные отгрузки значительно тельно, экспорт не может играть большой роли в ниже Группы «А». Для других Групп ННК объем деятельности таких компаний.

\section{Библиографический список}

1. Есть ли будущее у сектора российских независимых нефтяных компаний?- Энергетический центр Московской школы управления СКОЛКОВО, февраль 2014 г.

2. Основные вызовы для российской нефтяной отрасли,- Материалы Годового собрания «Ассонефть», 8 января 2015 г., г. Москва.

3. Козеняшева М.М. Независимые нефтяные компании в России и в мире: проблемы налогообложения // Нефть, Газ и Право.-2016. - № 4.- С. 33.

4. Конторович А. Э. Глобальные проблемы нефти и газа и новая парадигма развития нефтегазового комплекса России. [Электронный ресурс]: Новости Сибирской науки._ URL: http://www.sib-science.info/ru (дата обращения: 08.04.2019).

5. ИНК: первая нефтяная в Восточной Сибири. [Электронный ресурс]: Бизнес России. - URL: https://glavportal. com/materials/ink-pervaya-neftyanaya-v-vostochnoj-sibiri// (дата обращения: 08.04.2019).

6. Рассчитано по данным ФГУП ЦДУ ТЭК «Добыча нефти и газового конденсата» за 2020 год.

7. Спрос на нефть в Китае упал на $20 \%$ на фоне распространения коронавируса - URL: https://www.interfax.ru/ business/693780// (дата обращения: 08.02.2020).

8. Добыча нефти в России: 1991-2021 гг.- URL: http://global-finances.ru/dobyicha-nefti-v-rossii-po-godam// (дата обращения: 06.02.2020).

9. Курс доллара США в 2020 году: URL: http://ratestats.com/dollar/2020/.

10. ФГУП ЦДУ ТЭК «Добыча нефти и газового конденсата» за 2020 год.

11. ФГБУ «ЦДУ ТЭК». «Поставка нефтяного сырья прочих организаций на внутренний рынок и экспорт России» в 2020 году. 